\title{
ELTEATRO NEGRO DE BAHÍA: ENTRE AUSENCIAS, PRESENCIAS Y RESISTENCIAS
}

\author{
THE BLACK THEATER OF BAHIA: AMONG ABSENCES, \\ PRESENCES AND RESISTANCE
}

\author{
JÚLIA MORENA COSTA*
}

Resumen: Considerado el territorio brasileño más negro -su población está constituida por un $80 \%$ de negros-, Bahía está marcada en sus construcciones culturales y artísticas por los efectos de la diáspora transatlántica y produce un Teatro Negro pautado por la herencia cultural afro en sus composiciones escénicas y textuales, y enfocado en una referencialidad litúrgica que trasciende lo religioso. A partir de las referencias históricas del Teatro Negro brasileño y sus reverberaciones, este artículo se propone presentar una breve historiografía y reflexionar cómo el Teatro Negro producido en Salvador y en Alagoinhas (Bahía/Brasil) se articula de acuerdo con una lógica de colectividad, que puede ser pensada como una práctica de producción teatral, pero, principalmente, como un modo de operación solidaria y de fortalecimiento entre grupos. El episteme buscado por el Teatro Negro concierne a la relación entre la cultura afro de resistencia y la producción colectiva. El artículo se propone pensar el Teatro Negro en su ámbito de producción estética, que provoca el diálogo entre los conocimientos afrocentrados y occidentales, como propuesta política intrínseca a sus modos de producción aún periféricos dentro de un escenario brasileño. Para ello, se utilizará como ejemplo el grupo NATA (Alagoinhas) y se harán alusiones al Bando de Teatro Olodum (Salvador/BA).

Palabras clave: Teatro Negro, estética afrobrasileña, quilombo, Bahía, colectividad.

Aвstract: Regarded as the blackest Brazilian territory - with an $80 \%$ black population - Bahia is marked in its cultural and artistic constructions by the effects of the transatlantic diaspora, giving origin to a black theater guided by the Afro cultural heritage in its scenic and textual compositions, focused on a liturgical referentiality going beyond religiousness. From the historical references of the Brazilian Black Theater and its reverberations, this essay aims to present a brief historiography as well as to reflect on how the black theater produced in Salvador and Alagoinhas (Bahia / Brazil) articulates within a collective logic, which can be thought of as a practice of theatre production, but, mainly, as a form of solidary and strengthening operation among groups. The episteme gathered by the Black Theater refers to the relationship between the Afro culture of resistance and collective production. The proposal is to think the black theater in re-

* Doctora en Literatura y Cultura. Profesora de la Universidad Federal de Bahía, Salvador de Bahía, Brasil. Correo electrónico: juliamorenacosta@gmail.com. Orcid: https://orcid.org/0000-0002-22729893 
gards to its aesthetic production, which provokes the dialogue between Afro-centered and occidental knowledge as an intrinsic political proposal to its yet peripheral modes of production within the Brazilian scenario. The group NATA (Alagoinhas) will be used as an example and allusions will be made to the Bando de Teatro Olodum (Salvador / BA).

Keywords: Black Theatre, Afro-Brazilian Aesthetic, Quilombo, Bahia, Collectivity.

Recibido: 17.07.2020. Aceptado: 01.10.2021.

$\mathrm{E}$ L Teatro Negro, que cada día cuenta con nuevos grupos y agentes, se multiplica por el territorio brasileño. Este teatro tiene una larga trayectoria en los movimientos sociales y artísticos que tratan de traer a la escena $\mathrm{y}$ al escenario los saberes afrodiaspóricos. Con un posible origen ${ }^{1}$ que se remonta a fines del siglo XIX ${ }^{2}$, y con una extensa gama de actores, actrices, dramaturgos, coreógrafos y colectivos a lo largo del siglo XX, percibimos el Teatro Negro como fundamental para entender el teatro brasileño, aunque por mucho tiempo haya sido escamoteado de su historiografía. El teatro, insertado en una sociedad racista como la brasileña, guarda todavía espacios de poca visibilidad de las producciones de los sujetos negros, así como de las estéticas y epistemes afro. En este artículo nos centraremos especialmente en la constitución del Teatro Negro de fines del siglo XX e inicios del siglo XXI, en especial en Bahía. Régia Mabel Freitas (2017) remonta el término Teatro Negro al comienzo del siglo XX, cuando algunas compañías asumen el término "negro" en esa expresión teatral, intensificando el posicionamiento artístico-ideológico ${ }^{3}$. Por todas esas cuestiones, en este artículo se utilizará el término Teatro Negro, por entenderlo como un operador teórico, político y práctico importante y consistente en el contexto brasileño.

Uno de los desafíos al definir la importancia del Teatro Negro está en el reconocimiento brasileño de su existencia como creación y manifestación dotada de características propias y, por eso, merecedora de un título que indique su visibilidad. En su heterogeneidad de entendimiento, consideramos, en este artículo, el Teatro Negro como aquel que trae a la escena los

\footnotetext{
${ }^{1}$ Debido a la escasez de registros de las manifestaciones culturales y artísticas de los negros en un Brasil marcado por el racismo y reciente esclavización, se hace muy difícil precisar cuáles fueron las primeras manifestaciones teatrales protagonizadas por negros en el país.

${ }^{2}$ En 1880, Xisto Bahia excursiona por el nordeste y sudeste y presenta en el Rio de Janeiro la obra Os perigos do coronel, con la presencia de D. Pedro II.

${ }^{3}$ Régia Mabel Freitas cita como principales ejemplos, De Chocolat, Companhia Negra de Revistas (1926), Companhia Teatral Ba-Ta-Clan Preta (1927) y Teatro Experimental do Negro (1944).
} 
cuerpos negros, así como una elaboración temática y estética que responda a la cultura afrodiaspórica y a las demandas sociales, políticas y artísticas de ese grupo social. Es importante señalar que al mencionar los sujetos negros se está refiriendo al color de sus cuerpos, pero, también, a sujetos sociales inmersos en condiciones históricas específicas en un país como Brasil. Como defiende Leda Maria Martins (1995): "el color de un individuo no es nunca simplemente un color, sino un enunciado repleto de connotaciones e interpretaciones articuladas socialmente, con un valor de verdad que establece marcas de poder, definiendo lugares, funciones y hablas" (p. 35). Este trabajo es, por lo tanto, una contribución en el sentido de destacar una producción basada en la elaboración de una estética propia de los sujetos negros en Brasil y acorde con sus matrices culturales y con las discusiones sociales que tratan sobre sus experiencias, en especial en Bahía.

Una de las primeras propuestas colectivas escénicas de Teatro Negro político brasileño surge en 1944: el Teatro Experimental do Negro (TEN), creado por Abdias Nascimento junto con otros intelectuales. Con una propuesta explícitamente política en el teatro, se planteaba: "integrar al negro en la sociedad brasileña; criticar la ideología de la blancura; valorar la contribución negra a la cultura brasileña; mostrar que el negro era dotado de visión intelectual y dotar los escenarios de una dramaturgia intrínsecamente negra" (Lima, 2011, p. 83) . De acuerdo con Lima, el TEN era una "voz disonante en un contexto social en el cual la nación no reconocía, siquiera, ser ella un agente de discriminación racial" (2011, p. 83). La negación del racismo existente dificulta la creación de estrategias y actos de confrontación al mismo. Bajo la égida de democracia racial, muchas acciones de combate al racismo son acusadas de incitar justamente al supuesto odio entre las razas, por evidenciar sus diferencias sociales. Es fundamental destacar que esa supuesta democracia racial se desmiente por los espacios de vida socialmente delineados. Aunque cuente con una población mayoritariamente negra, alcanzando más de un $50 \%$ en Brasil y un $80 \%$ en Bahía, la población negra todavía tiene, con respecto a la población blanca, menores índices educacionales, menores remuneraciones (por los mismos trabajos) y un mayor índice de letalidad. Por lo tanto, resituar los lugares de representación del negro dentro de la sociedad brasileña, así como la militancia por el acceso a los bienes simbólicos y materiales, se vuelve de suma importancia, valorando sus culturas y los sujetos que las constituyen, desplazando los lugares comunes de ocupación como los descritos anteriormente.

\footnotetext{
${ }^{4}$ Todas las traducciones del portugués al español de este artículo son mías.
} 
Leda Maria Martins (1995), sobre los roles hasta el siglo XX preponderantes en el teatro brasileño para los personajes negros, los separa en tres categorías: esclavo fiel, pernicioso y cómico/grotesco. En ese teatro, "el habla del negro no es nunca su voz y, menos aún su discurso" (p. 43), reservando a los personajes blancos las características de lo bueno y de lo bello, y a los negros su inverso. Es importante, en ese sentido, referenciar y reverenciar el Teatro Experimental do Negro (TEN) que desplazaba las representaciones clásicas del negro y modificaba la escena teatral en Brasil por promover el protagonismo de los actores negros, en personajes humanizados e incentivando la creación de obras de Teatro Negro. Abdias Nascimento, en sus proposiciones militantes y estéticas teatrales, defendía el retorno a la Madre África, a diferencia del promulgado retorno a África o del separatismo étnico divulgado en Estados Unidos en ese momento. Es decir, el concepto de negritud recreado y defendido en Brasil por Abdias Nascimento y Guerreiro Ramos buscaba los orígenes, herencias y elaboraciones africanas del negro en el interior de la sociedad brasileña y no en África propiamente (Douxami, 2001, p. 322) . Bahía, marcada por una mayoría poblacional negra, pero, principalmente, por mantener y resaltar de forma explícita y aguda la influencia de la cultura afrodiaspórica, se hizo un centro de referencia, siendo considerada desde ya por TEN como la África Mítica de Brasil. Esa acepción puebla el imaginario brasileño y local, traduciéndose como un intenso y productivo movimiento cultural afro en Bahía y, en especial, en Salvador, lo que posibilita una profusión de grupos de Teatro Negro, en los cuales se destaca el Bando de Teatro Olodum como una de las referencias principales.

Remontando a los inicios del siglo XX, la participación negra en los escenarios bahianos era extremadamente restricta, limitada a pequeños personajes coadyuvantes y estereotipados. La fundación de la Escola de Teatro da UFBA, en 1956, promovió una profesionalización del teatro local y la formación de actores negros que vendrían a componer una mayor pluralidad en el espacio escénico de la ciudad y, en esa misma década, surgieron las primeras obras con temáticas negras o de las tradiciones populares ${ }^{6}$.

\footnotetext{
${ }^{5}$ En esa perspectiva, interesaba buscar dentro de la cultura brasileña los lazos y rastros de mantenimiento de la cultura afro con sus diferencias y continuidades. Esta propuesta se diferencia del deseo de retorno al continente africano y se aproxima a un deseo de pensar África como un espacio mítico dentro de Brasil.

${ }^{6}$ Citamos, por ejemplo, las obras O tesouro de Xica da Silva (1958), con temática negra y Uma véspera de Reis (1960), de temática valorativa de las tradiciones populares; y el Auto da Compadecida, de Ariano Suassuna (1959), que protagonizó Mário Gusmão, figurando un negro en escena en un papel destacado.
} 
La primera experiencia de Teatro Negro formalmente influenciada por TEN en Bahía se dio con la fundación del grupo TENHA (Teatro Negro da Bahia), creado por la directora y dramaturga Lúcia de Sanctis, en 1969, durante la dictadura militar brasileña. Lamentablemente, el grupo tuvo una vida corta, y se deshizo bajo fuertes y falsas acusaciones por parte de la prensa de ser innecesario en un escenario supuestamente libre de racismo y, por lo tanto, discriminatorio con los blancos. Además de la iniciativa de TENHA, destacamos que hubo también una serie de proyectos individuales o colectivos de montajes de obras que tematizaron problemáticas negras durante esa y las siguientes décadas e hicieron frente a un discurso de invisibilización de la cultura negra bajo fuerte presión del gobierno dictatorial. En 1990, a partir de un taller en el bloco afro de carnaval Olodum ${ }^{7}$, nace el Bando de Teatro Olodum, dirigido por Marcio Meirelles, Chica Carelli, Maria Eugênia Milet y Leda Ornelas. Creado inicialmente en colaboración con el Grupo Cultural Olodum, el Bando se hizo independiente y un colectivo con numerosa producción teatral, cinematográfica y cultural. Hoy en día, congrega más de 25 artistas negros de diferentes generaciones. En 1998, se funda el Núcleo Afro-brasileiro de Teatro de Alagoinhas - NATA, en la ciudad de Alagoinhas, que comienza como un grupo colegial, pero luego se profesionaliza y se inspira en los orikis, y usa teatro, danza afro y música. En 2000, el actor y director Ângelo Flavio funda el Colectivo Abdias Nascimento (CAN), en el ámbito académico, que funciona también como centro de investigaciones. Al retomar la historia de los grupos y espectáculos de Teatro Negro surgidos en las últimas décadas, se puede resaltar la gran producción escénica afrodiaspórica y para la pertinencia de la universidad, de las iniciativas anteriores locales y nacionales, de los centros culturales y de los blocos afro (gremios culturales, musicales y de danza) para el fomento de Teatro Negro de la ciudad.

Es importante resaltar que

El resurgimiento del Teatro Negro en Bahía, en la década de 1970 [y su continuidad en las décadas siguientes], no puede considerarse como un elemento artístico independiente, sino como parte de un movimiento artístico y estético general en la capital de Bahía. (Douxami, 2001, p. 352)

El crecimiento, en el último siglo, de la valoración de la cultura negra, de los blocos afro, de la música, danza, fiestas populares y religiosas de ma-

\footnotetext{
${ }^{7}$ Los "blocos afro de carnaval" de Bahía son asociaciones dedicadas al fomento de la cultura negra y surgieron a partir de los años setenta del siglo XX.
} 
triz africana fueron fundamentales para fomentar, también, la profusión de los grupos y obras de Teatro Negro en Bahía. El Teatro Negro necesita ser pensado como una red de grupos que, directa o indirectamente, se alimentan y que también dialogan con todo un escenario artístico y cultural negro, fortaleciéndose en esa colectividad, tanto directamente -como en la realización de intercambios, talleres, encuentros, foros, etc.-, como indirectamente, en creación de público, actores, dramaturgos y de preparación de una sociedad para aceptación y acogimiento de ese arte antes menospreciado (en eso actúan, además de teatro, también la música, el carnaval y los blocos afro, las fiestas populares, los actos religiosos, etc.). Los grupos afro-estético-culturales actúan en la transformación del imaginario y en la afirmación de una nueva estética en la ciudad de Salvador en diferentes áreas artísticas. En ese sentido, el teatro puede ser entendido como un espacio de colectividad propicio que fisura las fuerzas individualizantes de un mercado y de una sociedad que marginaliza algunos de sus sujetos, sea en el espacio artístico, sea en el acceso a los bienes sociales, materiales y culturales. Esa perspectiva se acerca a la idea de quilombo, término ampliamente usado en América Latina, para designar los lugares y concentraciones políticamente organizadas de negros esclavizados o ex esclavizados que conseguían encontrar salidas de la esclavización y que hoy todavía concentran comunidades surgidas de esos eventos históricos. Esas comunidades fueron y son responsables del fomento de la libertad de esos sujetos y de sus manifestaciones religiosas y culturales 8 .

El término quilombo 9 , evocado por TEN en el bautismo de su publicación que funcionó entre 1948 y $1950^{10}$, fue y sigue siendo retomado y resignificado, alcanzando funciones aún pertinentes para los desafíos de la

\footnotetext{
${ }^{8}$ El historiador Marco Aurélio Luz (2000), al señalar la importancia de los quilombos históricos y actuales, afirma que "los Estados-comunidad negros repartidos por las Américas constituyen una formación social paralela, cuyos valores se caracterizan por una continuidad transatlántica de la tradición africana que antagoniza con la estructura y los valores imponentes imperialistas coloniales" (p. 263).

${ }^{9}$ Abdias Nascimento utilizó ampliamente el concepto de quilombo, inicialmente como propuesta de organización, autonomía y autoría negra. Posteriormente, a partir del concepto de "quilombismo", lo utilizó tanto como estrategia político-social de enfrentamiento al racismo como para la construcción de una sociedad inspirada en la experiencia histórica de los quilombos brasileños y de experiencias de referencias negras. Se trata, por lo tanto, de un proyecto de emancipación social y colectiva del negro, basado en su propia historia y en su propia cultura de matriz africana, contraponiéndose a la negación del legado africano en las narrativas coloniales o a la reducción del negro a coadyuvante de los procesos históricos de la humanidad.

${ }^{10}$ Jornal Quilombo fue lanzado en 1948 por TEN, con el propósito de divulgación de sus piezas teatrales y como medio de desarrollar su crítica al racismo y al mito de democracia racial brasileño, así como la valoración de los sujetos negros. Se puede acceder a sus diez ediciones en facsímil en: http:// ipeafro.org.br/acervo-digital/leituras/ten-publicacoes/jornal-quilombo-no-01/
} 
sobrevivencia del arte marginal y/o periférico y no comercial producido en épocas poco democráticas como las vividas por Brasil actualmente. A partir de prácticas colaborativas y de fortalecimiento de los grupos y del público, se va creando una red de colectividad y resistencia a los sistemáticos ataques al área cultural, en especial a los que cuestionan los lugares clásicos de representación, y fomentan un escenario positivo de producción teatral en Bahía. El Teatro Negro se vuelve, entonces, espacio de un aquilombamiento simbólico de grupos de personas, tratando de crear espacios de existencia de una cultura, una estética, un saber que no cuenta con una circulación hegemónica dentro de la sociedad, discutiendo, muchas veces también estrategias de sobrevivencia de los cuerpos físicos de la comunidad negra, la más agredida por la violencia presente en el racismo brasileño. En medio de una sociedad hostil y aún predominantemente racista, surgen espacios de desarrollos culturales y estéticos afrodiaspóricos y de fortalecimiento de esos sujetos-artistas dentro del escenario teatral brasileño. Varios son los grupos que, en esa perspectiva, actúan en el sentido de fortalecer directa o indirectamente la comunidad artística negra local y nacional, y en la valoración de las producciones y de las vidas de los sujetos negros en general ${ }^{11}$. Como ejemplo cito los diversos talleres sobre Teatro Negro realizados por Bando de Teatro Olodum, por NATA, por CAN, entre otros ${ }^{12}$. Otro ejemplo concreto es la realización de Fórums de Performance Negra. El primero, realizado en 2005, por Bando de Teatro Olodum ${ }^{13}$, Cia dos Comuns (RJ) y Teatro Vila Velha, reúne y mapea desde entonces compañías negras de todo el país, con intercambios de experiencias y debates de los procesos creativos y transformadores de sus prácticas. Desde el 2017, el Fórum Negro das Artes Cênicas, hoy rebautizado como Fórum Negro de Arte e Cultura, para abarcar también otros lenguajes artísticos, reúne artistas e investigadores para debatir los desafíos y nuevas configuraciones de los discursos

\footnotetext{
${ }^{11}$ Nos parece importante enfatizar que la propia percepción de NATA como Teatro Negro se ve fortalecida en gran medida por la existencia de los grupos Bando de Teatro Olodum, CAN y Cia dos Comuns, como ha declarado la dramaturga y directora Onisajé (Fernanda Júlia) (2015, p. 94). Esta influencia y apoyo de los grupos antes mencionados también fue abordada por Onisajé (2017) en el artículo A formação de uma encenadora negra: o encontro com três coletivos negros.

${ }^{12}$ Los talleres citados son de actuación y también sobre la historia del Teatro Negro, estrategias de teatro colectivo, de captación de recursos y de profesionalización técnica, así como de vestuario, escenario, iluminación, etc.

${ }^{13}$ Otras iniciativas del Bando de Teatro Olodum en parcería con el Teatro Vila Velha son: Festival A cena tá preta y Proyecto Terças Pretas (que reúne shows musicales, teatro, filmes, literatura, lecturas dramáticas, charlas, talleres, performances y danza, con diversos artistas y afro emprendedores exponiendo producciones artesanales, moda y gastronomía).
} 
político-artísticos involucrados en el quehacer artístico actual ${ }^{14}$. Otra estrategia de fortalecimiento es la de formación de público, que genera una mayor proximidad entre los sujetos sociales y las producciones escénicas de los grupos de Teatro Negro, a través de tácticas como presentaciones en espacios alternativos, abaratamiento de entradas, exclusividad de funciones para escuelas y otros públicos específicos, como un esfuerzo en el sentido de aproximar un público cada vez más amplio a las producciones teatrales. Meirelles, por ejemplo, en entrevista concedida al investigador Marcos Alexandre (2017) cuenta que Bando de Teatro Olodum empezó a dar descuentos de $50 \%$ en el valor de las entradas para los espectadores negros en sus presentaciones, lo que generó un aumento significativo de ese público en los espectáculos:

A partir de entonces, el público de Bando, que notamos que era mayormente blanco, se volvió mayormente negro. Bando también trajo a esta audiencia a Vila Velha [espacio teatral en el centro de Salvador, conocido por su papel político en los años dictatoriales y hoy], para otros espectáculos de Vila Velha. El estreno de El sueño de una noche de verano de Shakespeare estuvo lleno de negros en la audiencia, en su mayoría negra. (...) el Bando y el público se apropiaron de un patrimonio de la humanidad, [que] también es nuestro, es patrimonio del negro y del blanco. (p. 348)

La cita anterior nos interesa por dos cuestiones. La primera se refiere a estrategias de formación de audiencia negra para las propias obras de Bando como también para otros grupos de Teatro Negro, así como para el teatro en general, aproximando una parte de la población que, hasta entonces, usualmente se mantenía alejada de los teatros y promoviendo la entrada de un público en espacios antes restrictos a la población blanca. Así, se establece un canal de proximidad y hábito con el quehacer escénico que fomenta la producción teatral local como un todo y en especial del Teatro Negro. Estrategias como esa funcionan también como un factor del aquilombamiento anteriormente mencionado, por fomentar espacios de fortalecimiento de

\footnotetext{
${ }^{14}$ Destacamos aquí también la creación del Festival de Dramaturgias da Melanina Acentuada, promovido desde 2012, en Salvador, Rio de Janeiro y São Paulo, reuniendo presentaciones de piezas teatrales, charlas, debates y talleres sobre Teatro Negro. Como uno de los frutos, se inauguró el 2018 una plataforma colectiva, el Portal Melanina Digital, que reúne un banco de obras dramatúrgicas firmadas por dramaturgos negros, considerado el mayor de este estilo en el país. Disponible en: https:// melaninadigital.com/
} 
grupos y sujetos atravesados por las vivencias raciales y sociales de un país con un largo pasado esclavista y tremendamente desigual en el acceso a los bienes materiales y simbólicos. Por otra parte, esa cita, al mencionar las herencias culturales también señala otra característica del Teatro Negro que nos interesa en este artículo: el espacio de encrucijada de saberes en que se establecen canales de negociación de archivos culturales distintos, africanos y europeos, una "encrucijada cultural" que legitima históricamente el uso simultáneo de las referencias tanto occidentales como africanas. Dicho operador teórico para el entendimiento del Teatro Negro, propuesto por Leda Maria Martins (1995), nos ayuda a abordar la unión de técnicas y temas teatrales occidentales a cuestiones, interpelaciones, estéticas y epistemes negras que conforman ese teatro que funciona como un operador de la negociación cultural de un pueblo diaspórico que, para sobrevivir a los ocultamientos culturales, tuvo que negociar sus referencias, y encontrar nuevas formas de enunciar: "Estos gestos nos revelan el ingenio liminal negro y un sutil proceso de difusión y arraigo, en la cultura brasileña, de la gnosis africana, resaltada entre las líneas de los discursos y en la constitución del conocimiento" (Martins, 1997, p. 156).

La encrucijada, entendida como operador práctico, de negociación cultural, encuentra sus bases dentro de la episteme afrodiaspórica religiosa brasileña, bajo la patente del orisha Exu, que

simboliza un importante principio estructural de la cultura negra, un operador semántico de la otredad africana en su intersección cultural en los Nuevos Mundos. Señor de la encrucijada y, sobre todo, de la encrucijada de los sentidos y los discursos, es un trickster, una instancia de mediación y significado a través del cual la mitología yoruba se desliza a través de la religión cristiana, manteniendo una enunciación diferenciada y descentralizadora. (Martins, 1995, p. 56)

La liturgia aquí debe ser comprendida no solamente como práctica religiosa o tema de obras escénicas, sino como componente de cosmovisión y como punto de contacto y afecto con el público y la comunidad afrodiaspórica. Además de las cuestiones subjetivas de la fe, el candomblé también puede ser pensado como punto de constitución de identidades culturales de estos pueblos, incluso por aquellos que no lo profesan directamente. La religión es un gran eje articulatorio de la cultura afro que sobrevive, sobre todo, en el cuerpo de los vivos, transmitida y actualizada oralmente y por los gestos, vivencias e historias. Una cultura fomentada, rescatada, 
guardada y trabajada principalmente en los terreros de candomblé15 y otros espacios religiosos, en los cuales los preceptos, con la preciosidad que le es destinada, son transmitidos oralmente, en las danzas, fiestas, comidas y rituales a través de los siglos. Los terreros-comunidades de axé (espacios dedicados a la vivencia de la fe afrodiaspórica), por lo tanto, fueron y son espacios de resguardo de la existencia de ese lenguaje que no tiene lugar en los libros y que no se limita a la palabra escrita, sino que necesita el cuerpo viviente y pulsante.

Los terreros de candomblé y otras religiones de matriz africana son los espacios en gran parte responsables del mantenimiento de los eslabones culturales de la población negra con su ancestralidad, en la actuación estética, de la fe, de la ritualidad y de la convivencia colectiva que permite una elaboración constante del significado de ser negro en una comunidad como la brasileña. Además, la ritualidad afrodiaspórica representada en una escena teatral, en su totalidad o en partes (gestos, elementos cromáticos, objetos litúrgicos, vestuario, frases, idiomas, etc.), logra crear un diálogo inmediato con una población que comparte ese saber, aunque no circule por las vías hegemónicas. Ese diálogo sucede inclusivamente para aquellos que no acceden a ese saber por la función religiosa o no profesan esa fe, pues esto ya forma parte de las manifestaciones culturales de esa población, aunque a veces no se consiga, para una parte de ella, percibir los lazos que la vincula a las religiones referenciales (véase la alimentación, celebración de fechas, colores votivos, vocabulario, idiomas, etc. que son compartidos por la población en general). La referencialidad religiosa en una población que mantiene sus rasgos afros con tal intensidad como la bahiana, aunque a veces suavizada por una cultura de negación o blanqueamiento de esos elementos, sobrepasa los círculos restringidos de quien participa de la fe, y alcanza gran parte de la población local. La performatización de esos elementos en el teatro, por lo tanto, al mismo tiempo que provoca gran afectación del público, ayuda a reforzar su importancia cultural, a resignificarla como elemento fundamental de una cultura que pasa por procesos constantes de blanqueamiento y reelaborarla de manera viva, trayendo, por consiguiente, importancia también para los sujetos que la profesan ${ }^{16}$.

\footnotetext{
${ }^{15}$ Los terreros de candomblé son espacios de vivencia y celebración religiosas de esta religión brasileña de matriz africana.

${ }^{16}$ En una serie de entrevistas con directores, dramaturgos y actores sobre el Teatro Negro en Bahia realizadas por la investigadora Douxami (2001), se señala que la importancia de las religiones de matriz africana es casi unánime, actuando sobre un 90\% de los grupos entrevistados (p. 352).
} 
En esta posibilidad de representación de la cultura afrodiaspórica que recurre a su repertorio histórico, cultural, estético y religioso, son necesarias búsquedas en otras grafías, no solamente la de los archivos escritos y canonizados por la perspectiva occidental. Los grupos de Teatro Negro, en su mayoría, buscan, además de las técnicas y aportes del teatro occidental, las referencias en los rituales, danzas, idiomas, técnicas y narrativas que circulan culturalmente por los bordes de lo hegemónico, a través de un saber escrito en el cuerpo, el gesto y la voz de los que viven en esa cultura. Con eso, el teatro gana en potencia, pues los cuerpos presentes pueden contar, representar y fomentar a partir de su carne, voces, gestos, canciones y ritmos aquello que la palabra escrita (o el cuerpo occidental) no puede decir. Esta afrografía ${ }^{17}$, que presentifica siglos de repertorio cultural, exige del público otra mirada, que entienda otras gestualidades de cuerpo, por donde circulan los gestos, las danzas, el ritmo, el habla y el soplo de una cultura. Marcos Alexandre (2017) recuerda que para esas presentificaciones hay un cuerpo negro pulsante del

actor negro en la escena que dispara un elemento impulsor que produce y, al mismo tiempo, integra una matriz ancestral, y trae consigo un vínculo con el continente africano; es una matriz / corpus de reminiscencias de recuerdos colectivos que se evocan cuando el cuerpo negro está actuando en su sentido como un rito, un trabajo performativo o una acción espectacular. (p. 40)

A partir de conceptos traídos a este artículo, procedemos a una breve presentación del grupo NATA y de su última obra escénica Oxum, por entenderla como producción que hace amplio uso de su lugar en el teatro para la creación de espacios de resistencia y (re)construcción de la representación de la cultura negra como marco civilizatorio de la cultura brasileña, acorde con lo que fue planteado anteriormente en este artículo. El Núcleo Afrobrasileiro de Teatro de Alagoinhas (NATA), como se mencionó anteriormente, fue fundado en 1998, en la ciudad de Alagoinhas, a $130 \mathrm{~km}$ de Salvador. En estos 20 años de trabajo, NATA realizó montajes teatrales,

\footnotetext{
${ }^{17}$ Afrografia es un concepto desarrollado por Leda Maria Martins (1997) al referirse a las grafías otras de la memoria que sobreviven y son fomentadas en los cuerpos de los sujetos que participan de comunidades afrodiaspóricas: "En el circuito tradicional, que mantiene la palabra ancestral, y en el circuito de transmisión, que la actualiza y mueve en el presente, la palabra es soplo, aliento, dicción, desempeño, índice de sabiduría. El lenguaje oral está inextricablemente vinculado al de los gestos, las expresiones y la distancia corporal (...) la palabra oral, por lo tanto, se realiza como lenguaje, conocimiento y disfrute porque combina, en su dicción y verificación, música, gesto, bailar, cantar” (pp. 146-147).
} 
talleres y lecturas dramáticas y gestionó proyectos que discuten y valoran la cultura afro-brasileña en Alagoinhas, Salvador y otras partes del interior de Bahía, además de otras regiones de Brasil. En las palabras de su dramaturga y directora, Onisajé (Fernanda Júlia):

nuestros espectáculos tienen la historia, la cultura y la religiosidad afrobrasileña como eje guía, con el objetivo de desmitificar los prejuicios y las imágenes peyorativas que pueblan histórica y culturalmente la imaginación colectiva de la sociedad, como resultado de un proceso de colonización y racismo. (2015, p. 87)

NATA se caracteriza por estar fuera de los ejes hegemónicos: afrocentrado, produciendo fuera de los principales circuitos teatrales (Río de Janeiro y São Paulo) y fuera de la capital baiana, en Alagoinhas: o sea, NATA ocupa también un lugar al borde en su producción y visibilidad. Hoy, el grupo mantiene ese carácter de tránsito entre los espacios hegemónicos y periféricos de la escena teatral, siendo premiado en importantes festivales y presentándose en los grandes y consagrados teatros de Salvador, así como en ciudades de interior, terreros de candomblé, áreas urbanas periféricas, etc., realizando un trayecto amplio que alcanza diferentes públicos.

En el campo de las encrucijadas, el grupo bebe de las fuentes occidentales y afrodiaspóricas, haciendo un diálogo de los ritos teatrales y religiosos, al proponer "el diálogo entre lo sagrado, en el teatro, y lo escénico de Candomblé" (Onisajé, 2015, p. 95). Las obras no son transposiciones literales de ceremonias para el escenario, sino que las toman como inspiración de los movimientos, con vestigios y proposiciones escénicas a partir del encuentro del ritual del teatro y del ritual del candomblé. El grupo desarrolló para ello una poética propia, que usa las técnicas de preparación y creación del teatro occidental pero también, y principalmente, los saberes filosóficos y rituales de las manifestaciones religiosas y culturales afrodescendientes, como el candomblé, la capoeira, el jongo y el macúlele. Onisajé, que es yakekerê ("mamá pequeña") ${ }^{18}$, desarrolló ejercicios escénicos de preparación, entrenamiento y formación de los actores a partir del encuentro de las manifestaciones populares y religiosas brasileñas con teorías teatrales y desarrolla en la actualidad una investigación escénica, la Activación del Movimiento Ancestral. Referida como la poética de NATA, parte del estudio profundizado de candomblé, bajo las perspectivas tanto litúrgicas

\footnotetext{
${ }^{18}$ Yakekerê auxilia a la sacerdotisa de mayor nivel jerárquico dentro del candomblé, la yalorixá. Onisajé, en tono explicativo, alegoriza la función como una "asistente de dirección" de los ritos.
} 
como culturales e historiográficas, y está construyendo un repertorio de ejercicios y disparadores de procesos escénicos y de concepciones visuales y sonoras de espectáculos. Onisajé (2015) define así la poética de NATA:

A través de la activación de la memoria cultural de la actriz / actor, y de su reconexión con los elementos conscientes o no de las deidades primordiales, en el caso de los Orishas, es posible adquirir un autoconocimiento que nos reconecta con nuestra historia cultural y corporal, sin dejar de dialogar con la investigación teatral contemporánea ya desarrollada. Estos son principios que se encuentran en diferentes campos y lenguajes, pero que convergen en nuevas formas de producir y actuar. (p. 92)

El candomblé se convierte, así, en materia prima de sus espectáculos $y$, a partir de una inmersión en los saberes afrografiados, se transforma en tema, procedimientos de preparación de actores y constructo de dramaturgia, en sus pautas más diversas, en la construcción de los personajes / personalidades, vestuario, concepción sonora y visual, diseño de luz y uso de las narrativas mito-poéticas, sumidas en la oralidad (a partir de los itans, orikis y orins ${ }^{19}$ ). En su última obra, Oxum (2018), por ejemplo, la primera totalmente dedicada a las mujeres, se escenifican diversas cualidades del orisha que nombra la pieza ${ }^{20}$. En las palabras de la directora artística, Onisajé (2017): "la revolución social es femenina y ha llegado la hora que la Mujer Negra hable de ella, por ella y sobre ella. Oxum es un espectáculo de empoderamiento femenino negro, donde las mujeres negras contemporáneas están llamadas a buscar su poder" (s.p.). En la pieza, también, se exponen atributos actualizados de Oxum, en la figura de lingüistas, musicólogos, entre otras funciones y profesiones, que cuestionan las representaciones negro-femeninas contemporáneas. Como es de praxis en la poética del grupo, las personalidades en el escenario son forjadas a través del acercamiento del actor / actriz a los arquetipos del orisha traído a la escena. Tal acto funda la tradición en la contemporaneidad y actualiza las cuestiones de Oxum, indicando su permanencia a través de los tiempos. Los gestos

\footnotetext{
${ }^{19}$ Itans son las leyendas de los Orishas. Orikis son los poemas en exaltación a los Orishas. Orins son los cantos para los Orishas y los ancestros. Para obtener más información sobre los procesos creativos y de preparación de los actores de la poética de NATA, consultar el texto Ancestralidade em cena: o teatro do NATA, de su directora y dramaturga Onisajé (2015).

${ }^{20}$ Son ellas: Opará - Justiciera y guerrera; Okê o Loke -cazadora; Abotô o Yaboto- el origen de Oxum, relacionada con el parto, al nacimiento y al encantamiento; y Ijimu, la hechicera y señora de la fecundidad.
} 
en escena, los cantos, la iluminación y el vestuario, así como las soluciones narrativas se forjaron dentro de una episteme que dialoga con el candomblé para no perder los lazos con el ahora de la platea y del grupo. En un escenario de desequilibrio causado por el patriarcado, Oxum, el arquetipo femenino relacionado con el amor, el encantamiento, pero también con la guerra y con la fecundidad, reacciona secando el mundo. Onisajé (2017) explica:

Los itans africanos nos muestran que durante los períodos de matriarcado las energías estaban equilibradas. Cuando el patriarcado se hace cargo, lastima a las mujeres y, en repudio a esto, las mujeres secaron el mundo que se volvió infértil. Oxum es un arquetipo de esta feminidad revolucionaria, del poder, del espacio para la lucha y la acción. (s.p.)

Así, el secado de las aguas y de la fecundidad son una respuesta a los actos humanos, además de ser un acto político. Al proponer una forma de actuación de la negación de participación en el juego de disputas de poder (secar los ríos, retirarse de las funciones atribuidas a ellas, salir de las relaciones afectivas) se propone también una estrategia para lidiar con el contexto social actual, indicando la fuerza y la importancia de las mujeres, en especial las negras, en los juegos sociales y en el campo del trabajo y familiar. Esta huelga de mujeres, marcada en la figura de Oxum, y actualizada por la música y referencias contemporáneas, toma también la participación de mujeres de la platea que son reverenciadas como diosas en el escenario y puede ser entendida en diálogo directo con la violencia doméstica e institucional que aún deja sobre los hombros de las mujeres, en especial de las negras, el mayor peso social, como en la mayoría de los países latinoamericanos. Se proponen, por lo tanto, creaciones de estrategias retóricas de combate a la violencia de género traducidas en lucha política afrocentrada, siendo un levantamiento contra el feminicidio negro y la invisibilización de la mujer negra en la contemporaneidad. En este breve ejemplo, de la obra escénica Oxum, de NATA, se materializa lo anteriormente planteado. El grupo, como uno de los muchos que hoy reafirman la importancia y la estética diversa del Teatro Negro producido en Bahía, dialoga en sus proposiciones formales, epistémicas y políticas, con la ancestralidad presente en la cultura negra.

Por último, al presentar este breve recorrido histórico del Teatro Negro de Bahía y algunos de sus conceptos operadores (espacio de agrupación y resistencia, locus de encrucijada y afrografías) en sus elaboraciones estéticas y políticas, no se pretende cerrar o agotar el tema. En el caso de las producciones escénicas brasileñas, aunque atravesadas por el racismo (como 
todas las demás áreas de este país), vienen surgiendo cada vez más piezas y grupos se están formando y actuando, reafirmando un lugar cada día más reconocido. Por todo ello, afortunadamente, el Teatro Negro no puede ser encerrado en una definición estancada, pues continúa siendo elaborado y transformado por sus agentes en sus producciones escénicas y teóricas fértiles y múltiples. Sea en la concepción de Teatro Negro que trae la presencia del cuerpo negro en escena, sea en la que recurre a sus temáticas o aquel que construye su dramaturgia y concepción visual y sonora a partir de epistemes afrodiaspóricas, las especificidades del hacer escénico negro han crecido, consolidado su lugar y fortalecido el teatro brasileño como un todo. Y, aunque los contextos políticos brasileños actuales se diseñen en el sentido contrario, esperamos que ese escenario sea cada día más de expansión; pues sabemos que en el camino trazado hasta aquí, la construcción fue de resistencia y lucha y los avances democráticos logrados hasta ahora no han sido en vano.

\section{REFERENCIAS}

Alexandre, M. (2017). O teatro negro em perspectiva: dramaturgia e cena negra no Brasil e em Cuba. Rio de Janeiro: Malê.

Azevedo, A. (1983). Teatro de Artur Azevedo. (Tomo 1. Instituto Nacional de Artes Cênicas-INACEN. V. 7: Coleção Clássicos do teatro Brasileiro). Rio de Janeiro: MEC.

Callado, A. (1969). O tesouro de chica da silva. Rio de Janeiro: Nova Fronteira.

Douxami, C. (2001). Teatro Negro: a realidade de um sonho sem sono. Revista Afro-Ásia, 26-25, 313-363. Doi: https://doi.org/10.9771/aa.v0i25-26.21016

Freitas, R.M. (2017). A história do teatro negro na Bahia: a força do discurso político-ideológico da negritude em cena. Repertório, 29, ano 20, 86-104.

Lima, E. (2011). Teatro negro, existência por resistência: problemáticas de um teatro negro brasileiro. Repertório, 17, 82-88.

Luz, M. (2000). Agadá - Dinâmica da civilização africano-brasileira (2a ed.). Salvador: EDUFBA.

Martins, L. (1995). A cena em sombras. São Paulo: Perspectiva.

Martins, L. (1997). Afrografias da memória. São Paulo/Bello Horizonte: Perspectiva/ Mazza Edições.

Onisajé (Fernanda Júlia). (2015). Ancestralidade em cena - o teatro do NATA. Repertório, 24, 86-97.

Onisajé (Fernanda Júlia). (2017). A formação de uma encenadora negra - o encontro com três coletivos negros. Repertório, 29, ano 20, 120-133. Doi: https://doi.org/10.9771/r.v0i29.25462

Suassuna, A. (2018). O auto da compadecida. Rio de Janeiro: Nova Fronteira. 